\title{
Analysis of Vitamin C (ascorbic acid) Contents packed fruit juice by UV-spectrophotometry and Redox Titration Methods
}

\author{
Samira Ben Mussa and Intisar El Sharaa \\ Department of Chemistry, Faculty of Science, Benghazi University-Libya
}

\begin{abstract}
Total vitamin C (ascorbic acid + dehydroascorbic acid) has been determined by UVspectrophotometric method in various fruit juices. In this method, a blended sample is homogenized with 3\% metaphosphoric acid-10\% acetic acid solu'an. Then addition of bromine water oxidizes ascorbic acid to dehydroascorbic acid in presence of acetic acid and the excess of bromine is removed by a few drops of 10\% thiourea. After coupling with 2,4-dinitrophenyl hydrazine at $37^{\circ} \mathrm{C}$ temperature for three hours, the solution is cooled in an ice bath and is treated with chilled 85\% H2SO4 to produce a red colour complex and the absorbance is measured spectrophotometrically at $521 \mathrm{~nm}$. This method obeyed Beer's law as was tested by using a standard ascorbic acid. Also ascorbic acid can be determined by redox titration. We performed an iodimetric back-titration in which we generated a measured excess of iodine in the sample solution and then we titrated the unreacted iodine with a standard sodium thiosulfate solution.

Our purpose is to determine the Vitamin C content in some packed (industrial) fruit juices and compare the values with that labeled on the packed fruit juices. The samples were collected from different markets in Benghazi.Such as Rhyhan, Mazraa, Judi, Alhanaa, Nadic, Viva, Rani, Bravo, Suntop, and Stantal of different kinds.
\end{abstract}

Key words: Vit. C, fruit Juices, iodimetric titration and UV-spectrophotometric.

\section{Introduction}

Human health is very important to our survival. Vitamins help the human to maintain a healthy diet. They serve as essential components of the specific coenzymes participating in metabolism and other specialized activities. Among the vitamins, vitamin C (ascorbic acid) is an essential micronutrient required for normal metabolic function of the body (Jaffe, 1984). Human and other primates have lost the ability to synthesize vitamin $\mathrm{C}$ as a result of a mutation in the gene coding for L-gulonolactoneoxidase, an enzyme required for the biosynthesis of vitamin $\mathrm{C}$ via the glucuronic acid pathway (Woodall \& Ames, 1997). Thus, vitamin $\mathrm{C}$ must be obtained through the diet. Vitamin $\mathrm{C}$ plays an important role as a component of enzymes involved in the synthesis of collagens and carnitine. Vitamin $\mathrm{C}$ is the major water - soluble antioxidant within the body (Sies \& Wilhlm, 1995; Levine el al., 1986 and Levine et al., 1995). It lowers blood pressure and cholesterol level (Rath, 1993). Not only does avitamin C intake markedly reduce the severity of a cold, it also effectively prevents secondary viral or bacterial complications. Numerious analysis have shown that an adequate intake of vitamin $\mathrm{C}$ is effective in lowerin the risk of developing breast cancer, cervix, colon, rectum, lung, mouth, prostate and stomach(Levine et al.,1996; Block, 1992; Feriet al., 1994; Block, 1991 and Jacobs, 1993). This vitamin is especially plentiful in fresh fruit and fruit juices, in particular citrus fruit, and vegetables (Bendich, 1997).

A lack of vitamin C in the diet causes the deficiency disease scurvy (Levine, 1986). This potentially fatal disease can be prevented with as little as $10 \mathrm{mg}$ vitamin C per day (Weber et al., 1996), an amount easily obtained through consumption of fresh fruit and vegetables. Other symptoms of its deficiency have been reported, but they are not well defined. It participates in numerous biochemical reactions, suggesting that vitamin C is important for every body process from bone formation to scar tissue repair (Grrof et al., 1995). Vitamin $\mathrm{C}$ is generally non - toxic. For maintaining a good and sound health and for prevention from common cold, human body should be kept saturated with vitamin C (Lehinger,1993). Keeping in view its importance; the estimation of vitamin $\mathrm{C}$ containing this vitamin assumes significance. A wide variety of food exists that contains vitamin C. It is widely known by the laypeople today that the best sources of vitamin $\mathrm{C}$ are citrus fruits and their juices. For better utilization of fruits and vegetables as a human food, clear understanding of their nutrition value as well the content of vitamin $\mathrm{C}$ estimation is essential (Rahman et al., 2005).

\section{Materials and Methods}

Methods which can be applied to determine vitamin $\mathrm{C}$ in fruits or vitamin supplement can be summarised into five methods such as direct titration with iodine solution, titration with dichlorolindophenol solution, using capillary electrophoresis with UV-VIS and diode array detection in high performance liquid 
chromatography [HPLC] (Shafqat ullah et al.,2012), using ion-pair reversed phase in HPLC and UV-diode detection and enzymatic method.

Although some methods are available for the determination of ascorbic acid but very few methods are employed for the determination of both forms (ascorbic acid and oxidized form, dehydroascorbic acid) of ascorbic acid. This is because of the two forms of the vitamin C: ascorbic acid and its oxidized form dehydroascorbic acid, and the different chemical, optical and electrochemical properties as well.

In the present research, vitamin $\mathrm{C}$ concentration was determined by two methods which are Redox Back Titration and UV- Visible Spectrophotometery.

\section{Determination of ascorbic acid by redox titration}

Although new methods and reagents are being discovered and developed continuously, , we do not have a convenient solution that reacts or complexes directly with the Vitamin $C$ to be analyzed. In these types of cases, we must perform our analysis indirectly by analyzing species that do react or complex with the species of interest. Vitamin C (Ascorbic Acid), is a mild reducing agent (it accepts electrons from an electron donor, leaving the Oxidation State of the donor at a value less than original (reduced). The Ascorbic Acid itself is oxidized to a higher oxidation state. This class of reactions is known as a oxidation reduction reaction or simply, a redox reaction. One such redox reaction is the reduction of the aqueous iodine molecule (I2(aq)) with Ascorbic Acid, as shown below.

$$
\begin{aligned}
& \mathrm{KIO} 3(\mathrm{aq})+6 \mathrm{H}+(\mathrm{aq})+5 \mathrm{I}-(\mathrm{aq}) \rightarrow 3 \mathrm{I} 2(\mathrm{aq})+3 \mathrm{H} 2 \mathrm{O}(\mathrm{l})+\mathrm{K}+(\mathrm{aq}) \quad \text { generation of } \mathrm{I} 2 \quad \text { (Eq.1) } \\
& \mathrm{C} 6 \mathrm{H} 8 \mathrm{O} 6(\mathrm{aq})+\mathrm{I} 2(\mathrm{aq}) \rightarrow \mathrm{C} 6 \mathrm{H} 6 \mathrm{O} 6(\mathrm{aq})+2 \mathrm{I}-(\mathrm{aq})+2 \mathrm{H}+(\mathrm{aq}) \quad \text { oxidation of vitamin } \mathrm{C} \text { (Eq.2) }
\end{aligned}
$$

Reaction (1) generates aqueous iodine, I2 (aq). This is then used to oxidize vitamin C (ascorbic acid, $\mathrm{C} 6 \mathrm{H} 8 \mathrm{O}$ ) in reaction (2). Both of these reactions require acidic conditions and so dilute sulfuric acid, $\mathrm{H} 2 \mathrm{SO} 4$ (aq), will be added to the reaction mixture. Reaction (1) also requires a source of dissolved iodide ions, I-(aq). This will be provided by adding solid or excess solution of potassium iodide, $\mathrm{KI}(\mathrm{s})$, to the reaction mixture.

\section{Determination of Ascorbic Acid By UV-Visible Spectrophotometery}

To determine the content of total vitamin $\mathrm{C}$ in fruit juices samples, a well - established method is the 2, 4-dinitrophenyl hydrazine (DNPH) (Qasi Mohammed et al., 2009). This is a simplified method for the simultaneous determination of the total vitamin $\mathrm{C}$ employed coupling reaction of 2,4- Dinitrophenyl hydrazine dye with Vitamin $\mathrm{C}$ and followed by spectrophotometric determination.

\section{Instrument}

A Double beam UV-Visible spectrophotometer (Model GESEYS 10uv) with $1 \mathrm{~cm}$ cell was used.

\section{Reagents required}

$5 \%$ Starch Solution, Sodium Carbonate, $(0.04 \mathrm{~N})$ Standard Potassium Iodate Solution, (0.03 N) Sodium Thiosulfate Solution, $10 \%$ KI Solution, 0.2 M Sulphuric acid solution, Sodium Carbonate, 3\% Acetic acid, $10 \%$ Thiourea, 2,4- Dinitrophenyl Hydrazine, $85 \%$ Sulphuric acid and Bromine water.

\section{Standard vitamin C (ascorbic acid) solution}

$0.05 \mathrm{~g}$ standard crystalline ascorbic acid was dissolved in $100 \mathrm{ml}$ distilled water to prepare $500 \mathrm{ppm}$ standard stock solution.

\section{Analysis of the Samples by Titration Method \\ Standardization of Sodium Thiosulfate Solution}

Pipette $5.00 \mathrm{ml}$ of the potassium iodate solution into a conical flask. Add $10 \mathrm{ml}$ of $10 \%$ potassium iodide and $10 \mathrm{ml}$ of dilute sulfuric acid to the conical flask. Titrate the liberated iodine with sodium thiosulfate solution from a burette until a faint yellow colour is reached.

Add 10 drops of starch solution and continue the titration until the blue-black colour of the starch - triiodide complex just disappears.

Repeat the titration until concordant results are obtained. Calculate the normality of the sodium thiosulfate solution.

\section{Titration of Standard Solution of Ascorbic Acid}

Pipette $5.00 \mathrm{ml}$ of the juice sample solution into a conical flask Repeat the steps as in the standardization of sodium thiosulfate solution from 1 to Calculate the concentration of the ascorbic acid from the relation:

milliequivalent of sodium iodate - milliequivalent of sodium thiosulfate $=$ milliequivalent of ascorbic acid 
Titration of fruit juice samples

Pipette $5.00 \mathrm{ml}$ of the treated juice sample in to a conical flask. Repeat the steps as with standard ascorbic acid.

\section{Amount of Ascorbic Acid obtained from Titration Method}

The amount of A.A is calculated from the expression:

$($ meq $\mathrm{KIO} 3-$ meq Na2S2O3) $=$ meq A.A

Analysis of the Samples by Spectrophotometric Method

\section{Preparation of standard calibration curve}

Prepare standard solutions of ascorbic acid containing 0 ppm, 5 ppm, 10 ppm, 15 ppm, 20 ppm 25 ppm, $30 \mathrm{ppm}$ in $25 \mathrm{ml}$ volumetric flasks from $500 \mathrm{ppm}$ stock solution of ascorbic acid. To each flask add few drops of bromine water to oxidize the ascorbic acid to dehydroascorbic acid. Then add a few drops of thiourea to remove the excess bromine and thus the clear solution was obtained. Add $1 \mathrm{ml}$ of glacial acetic acid and then $1 \mathrm{ml}$ of 2,4- DNPH solution to all standards and blank.

For the completion of the reaction, keep all the flasks at $37^{\circ} \mathrm{C}$ temperature for 3 hours in a water bath (thermostatic).

After this incubation, cool in an ice bath for half an hour and treat with $5 \mathrm{ml}$ of chilled $85 \% \mathrm{H}_{2} \mathrm{SO}_{4}$ with constant stirring. Complete the volume to the mark with distilled water.

Scan the spectra for determining the $\square_{\max }$ for the complex formed. Draw the calibration curve at the proper wavelength.

\section{Analysis of the samples}

Take $5 \mathrm{ml}$ from the supernatant liquid in a $25 \mathrm{ml}$ volumetric flask and complete the volume to the mark with $5 \%$ metaphosphoric acid $10 \%$ acetic acid solution. Take $5 \mathrm{ml}$ from the above solution in another $25 \mathrm{ml}$ volumetric flask. Repeat the steps from 3 to 6 as with the standard solutions.

Calculate the concentration of the ascorbic acid in the packaged fruit juice sample.

\section{Estimation of $\chi \max$ (Absorption maximum of ascorbic acid) \\ III. Results and Discussion}

To determine the absorption maximum, standard solutions of ascorbic acid in concentration of $30 \mathrm{ppm}$ were prepared. Scanning of the complex in a wavelength range from $350 \mathrm{~nm}$ to $650 \mathrm{~nm}$ showed a maximum absorbance $(\chi \max )$ at $521 \mathrm{~nm}$ as shown in figure 1 .

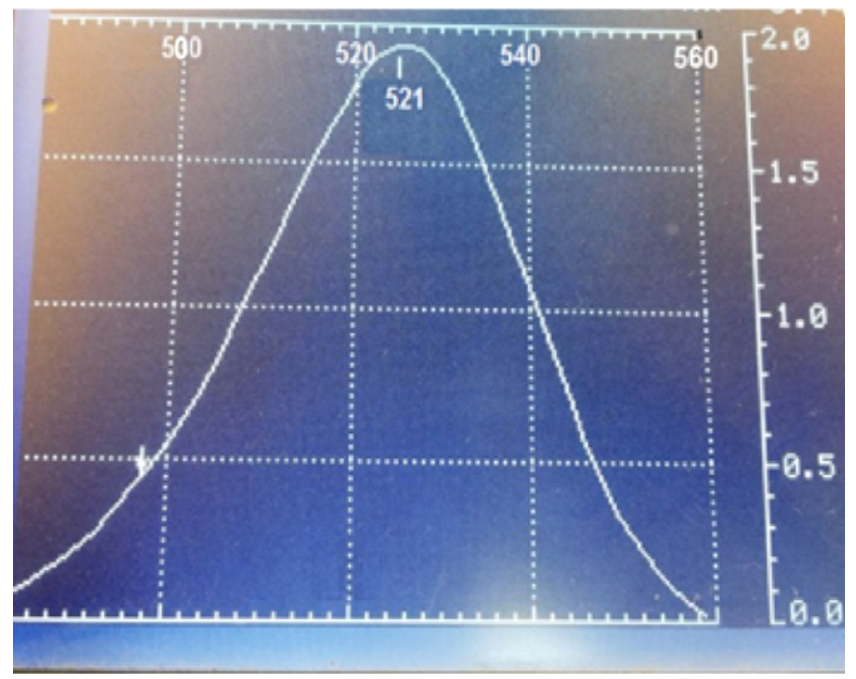

Figure 1: $\square \square_{\text {Max }}$ for Osazone Complex

\section{Calibration Curve}

After determination of the $\square$ Max of colored complex $(521 \mathrm{~nm})$ using spectrophotometer, the absobance of all standards $(0-30) \mathrm{ppm}$ in $25 \mathrm{ml}$ volumetric flasks from $500 \mathrm{ppm}$ stock solution of ascorbic acid. The calibration curve was constructef by plotting the concentration versus the corresponding absorbance (Fig. 2). The limit of detection LOD of ascorbic acid is $0.01 \mathrm{ppm}$ (3 бof 10 measurements of standard solution, LOQ of ascorbic acid is $0.017 \mathrm{ppm}$. The relative standard deviation was $2.4 \%$ for 10 measurments of standard solution of ascorbic acid concentration of $7 \mathrm{ppm}$.

Figure 2, shows the calibration curve of the osazone complex formed from a series of standard solutions of ascorbic acid. 


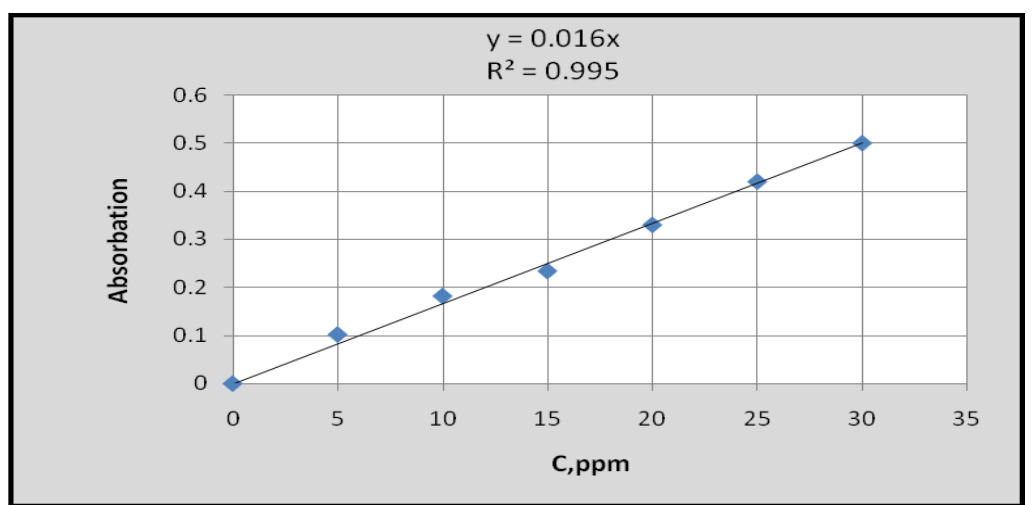

Figure 2: Calibration Curve of Standard Vitamin C at $521 \mathrm{~nm}$

\section{Amount of Ascorbic Acid in Packed Fruit Juices}

Table 1 shows the calculated concentration of vitamin $\mathrm{C}$ for various fruits for Rayhan and comparing them with the values labeled

Table 1 : Amount of Vitamin C for Calculated and Labeled in $\mathrm{mg} / 100 \mathrm{ml}$ for Rayhan, $\mathrm{n}=3$

\begin{tabular}{|c|c|c|}
\hline kind of fruit & $\begin{array}{c}\text { amount labeled } \\
\mathrm{mg} / 100 \mathrm{ml}\end{array}$ & $\begin{array}{c}\text { amount calculated } \\
\mathrm{mg} / 100 \mathrm{ml}\end{array}$ \\
\hline Apples & 10 & $9.27 \pm 0.00$ \\
\hline Guava & 10 & $9.41 \pm 0.42$ \\
\hline Mango & 10 & $8.34 \pm 0.00$ \\
\hline Peach & 10 & $9.68 \pm 0.00$ \\
\hline Pear & 10 & $9.27 \pm 0.00$ \\
\hline Banana & 20 & $18.54 \pm 0.21$ \\
\hline Mixed Fruit & 20 & $19.47 \pm 0.42$ \\
\hline Orange+Carrots & 20 & $19.45 \pm 0.10$ \\
\hline Cocktail & 30 & $29.65 \pm 0.42$ \\
\hline Pineapple & 30 & $26.88 \pm 0.42$ \\
\hline Orange & 35 & $32.45 \pm 0.10$ \\
\hline
\end{tabular}

From the table 1 and the figure 3, we note that there is a little difference between the amount labeled and the amount calculated, in all cases the amount calculated was little then labeled, that is refer to unstable vitamin.

The following tables ( 2 to10) show the calculated concentration of vitamin $\mathrm{C}$ for various fruits from different Companies in $\mathrm{mg} / 100 \mathrm{~mL}$.

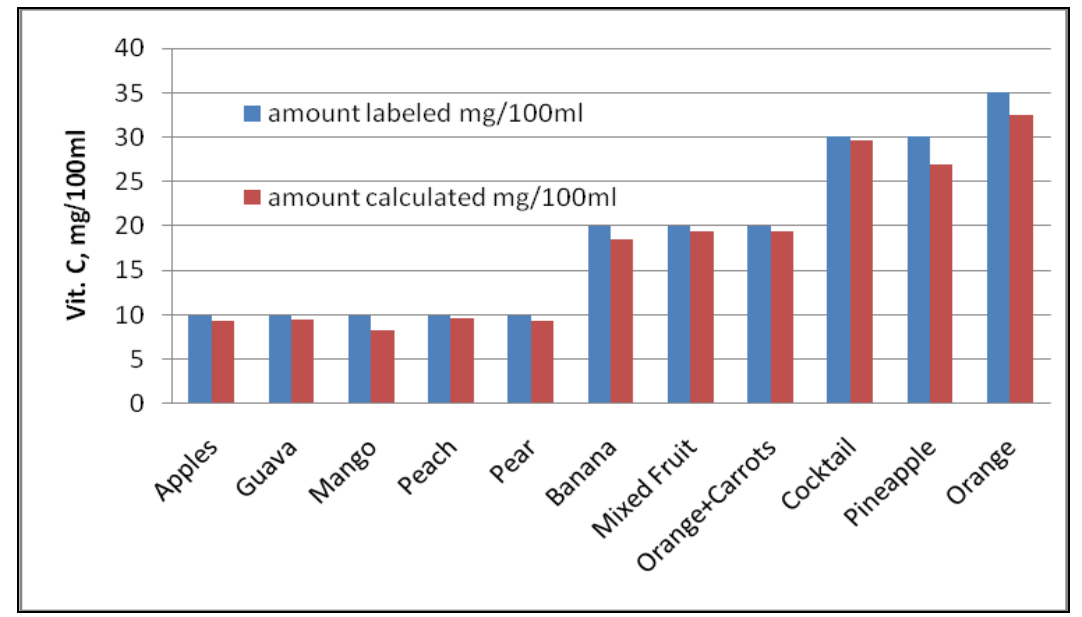

Figure 3: Amount of vitamin $\mathrm{C}$ for calculated and labeled in $\mathrm{mg} / 100 \mathrm{ml}$ for $\mathrm{Rhyan}$ 
Table 1: Amount of A.A from Judi Company, $n=3$

\begin{tabular}{|c|c|}
\hline kind of fruit & amount calculatedmg/100ml \\
\hline Pear & $16.68 \pm 0.10$ \\
\hline Banana & $19.16 \pm 0.437$ \\
\hline Pineapple & $16.44 \pm 0.415$ \\
\hline Guava & $8.05 \pm 0.00$ \\
\hline peach + apricot + Orange & $12.33 \pm 0.10$ \\
\hline Orange & $14.83 \pm 0.00$ \\
\hline Orange + Carrots & $15.56 \pm 0.415$ \\
\hline Peach & $8.51 \pm 0.00$ \\
\hline Mango & $8.54 \pm 0.00$ \\
\hline Cocktail & $28.18 \pm 0.00$ \\
\hline Apples & $7.93 \pm 0.10$ \\
\hline
\end{tabular}

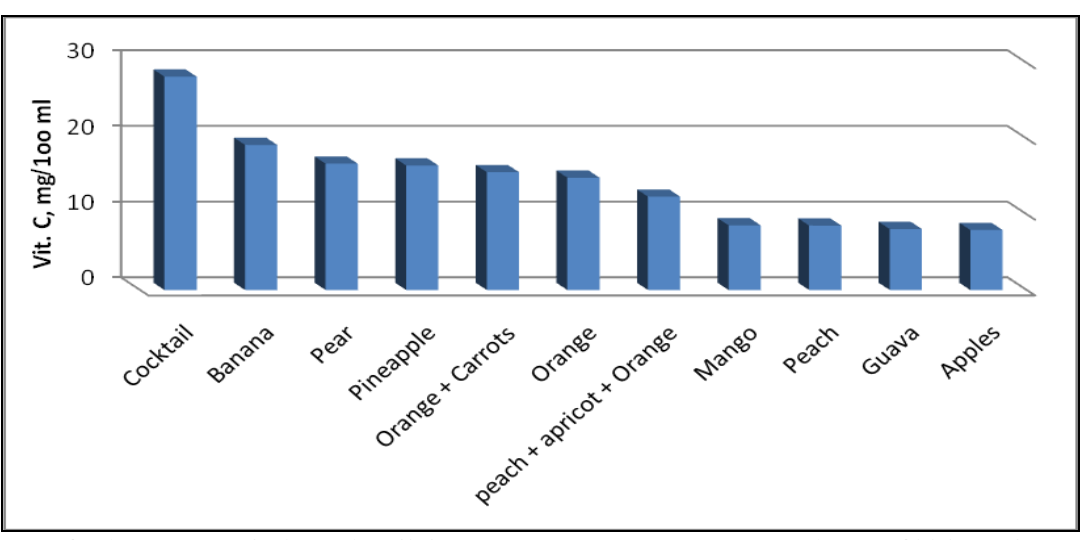

Figure 4: Amount of vitamin C for calculated and labeled in $\mathrm{mg} / 100 \mathrm{ml}$ for Judi

Table 2: Amount of A.A from Al Mazraa Company, $n=3$

\begin{tabular}{|c|c|}
\hline kind of fruit & amount calculated $\mathbf{~ m g} / \mathbf{1 0 0 m l}$ \\
\hline Pear & $9.27 \pm 0.00$ \\
\hline Banana & $18.54 \pm 0.00$ \\
\hline Pineapple & $26.83 \pm 1.31$ \\
\hline Guava & $9.1 \pm 0.42$ \\
\hline Orange + Carrots & $19.47 \pm 0.00$ \\
\hline Orange & $32.45 \pm 0.00$ \\
\hline peach + apricot + Orang & $19.08 \pm 0.42$ \\
\hline Cocktail & $29.65 \pm 0.42$ \\
\hline Mango & $9.27 \pm 0.00$ \\
\hline Apples & $8.34 \pm 0.00$ \\
\hline
\end{tabular}

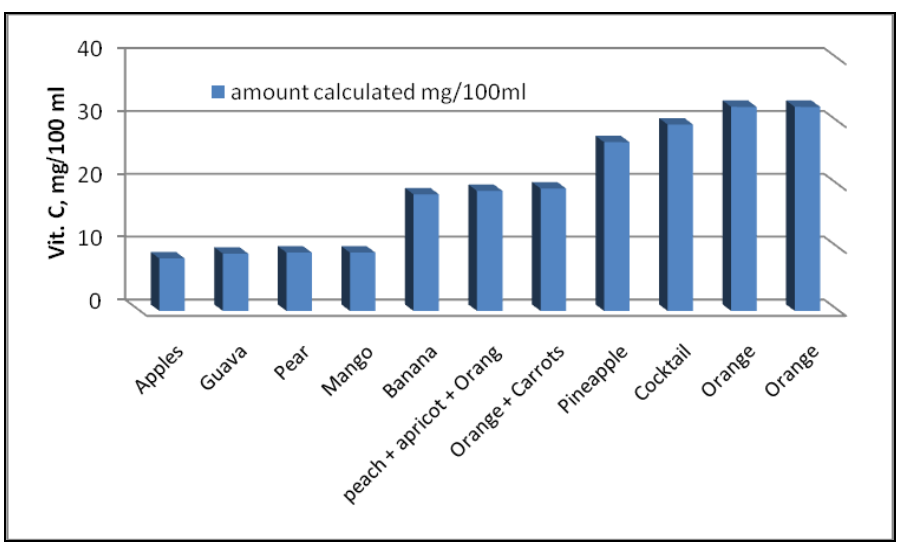

Figure 5: Amount of vitamin $C$ for calculated and labeled in $\mathbf{m g} / 100 \mathrm{ml}$ for Al Mazraa Table 4: Amount of A.A from Rani Company, $n=3$

\begin{tabular}{|c|c|}
\hline kind of fruit & amount calculated $\mathrm{mg} / 100 \mathrm{ml}$ \\
\hline Orange & $18.54 \pm 0.00$ \\
\hline peach & $22.24 \pm 0.00$ \\
\hline Red Grape & $14.83 \pm 0.00$ \\
\hline Banana+ Strawberry & $12.98 \pm 0.00$ \\
\hline
\end{tabular}


Table 5: Amount of A.A from Nadic Company, $n=3$

\begin{tabular}{|c|c|c|}
\hline kind of fruit & amount calculated $\mathbf{~ m g / 1 0 0 m l}$ & amount labeled $\mathbf{~ m g / 1 0 0 m l}$ \\
\hline Cocktail & $21.939 \pm 0.44$ & 40 \\
\hline Apples & $22.248 \pm 0.42$ & 25 \\
\hline
\end{tabular}

Table 3: Amount of A.A from SuntopCompany, $n=3$

\begin{tabular}{|c|c|c|}
\hline kind of fruit & amount calculated $\mathbf{~ m g} / \mathbf{1 0 0 m l}$ & amount labeled $\mathbf{~ m g} / \mathbf{1 0 0 m l}$ \\
\hline Orange & $23.18 \pm 0.10$ & 24 \\
\hline Mango & $23.18 \pm 0.00$ & 24 \\
\hline Cocktail & $23.18 \pm 0.15$ & 24 \\
\hline
\end{tabular}

Table 7: Amount of A.A from Viva Company, $n=3$

\begin{tabular}{|c|c|}
\hline kind of fruit & amount calculated $\mathrm{mg} / 100 \mathrm{ml}$ \\
\hline Pineapple & $5.87 \pm 0.44$ \\
\hline Guava & $16.69 \pm 0.00$ \\
\hline
\end{tabular}

Table 84: Amount of A.A from Alhanaa Company, $n=3$

\begin{tabular}{|c|c|}
\hline kind of fruit & amount calculated $\mathrm{mg} / 100 \mathrm{ml}$ \\
\hline Guava & $7.42 \pm 0.00$ \\
\hline Mango & $2.16 \pm 0.44$ \\
\hline Orange & $4.14 \pm 0.0$ \\
\hline
\end{tabular}

Table 9: Amount of A.A from Bravo Company, $n=3$

\begin{tabular}{|c|c|}
\hline kind of fruit & amount calculated $\mathbf{~ m g} / \mathbf{1 0 0 m l}$ \\
\hline Pineapple & $21.63 \pm 0.87$ \\
\hline Pear & $14.83 \pm 0.44$ \\
\hline Orange & $21.63 \pm 0.87$ \\
\hline
\end{tabular}

Table 10: Amount of A.A from Stantal Company, $n=3$

\begin{tabular}{|c|c|}
\hline kind of fruit & amount calculated $\mathbf{~ m g} / \mathbf{1 0 0 m l}$ \\
\hline Pear & $16.07 \pm 0.87$ \\
\hline Orange & $31.52 \pm 0.00$ \\
\hline Grapefruit & $36.78 \pm 0.44$ \\
\hline
\end{tabular}

\section{Amount of total vitamin C in Fruit Juices By Spectrophotometric}

Fruit juices which have interferences in the titration method were measured by using spectrophotometric methods as shown in table.

Table 11: The total vitamin $C$ content in Fruits in Some Juices, $n=3$

\begin{tabular}{|c|c|}
\hline Kind of juice & Vit. C in $\mathrm{mg} / 100 \mathrm{ml}$ \\
\hline Pineapple (Don Simon) & $25.22 \pm 1.32$ \\
\hline Grape (Don Simon) & $27.53 \pm 1.32$ \\
\hline Orange + carrots (Don Simon) & $33.48 \pm 0.66$ \\
\hline Mixed Fruit(Don Simon) & $40.82 \pm 0.63$ \\
\hline Grape (Don Simon) & $33.33 \pm 0.97$ \\
\hline Blueberry (Don Simon) & $35.65 \pm 0.72$ \\
\hline Peach Alain & $47.12 \pm 0.42$ \\
\hline Grape Alain & $27.44 \pm 0.92$ \\
\hline Cocktail Alain & $33.48 \pm 0.57$ \\
\hline
\end{tabular}

From the above table, it is clear that vit. $\mathrm{C}$ is high in these two types (Don Siemon and Alain) regardless of the kind of the juice

\section{Interferences due to diketogulonic acid}

Due to the destructive oxidation hydrolysis at higher $\mathrm{PH}$, this results in the opening of the lactone ring of the ascorbic acid and loose the vitamin activity. These processes naturally occurre in fruits, and some amounts ofdiketogulonic acid is present in the fruits (Geigertj et al., 1981). As the diketogulonic acid has keto group, it should give the osazone with DNPH as that of ascorbic acid and should give the colored complex on treatment with $85 \% \mathrm{H}_{2} \mathrm{SO}_{4}$. Thus there is chance of error in this method. But actually this cannot interfere with the ascorbic acid. Here diketogulonic acid was prepared by the acid hydrolysis of ascorbic acid. The spectrum shows that there is no considerable absorption peak near the $280 \mathrm{~nm}$ (the absorption maxima of DNPH complex of ascorbic acid). 


\section{Interference due to extracteglucose}

As ascorbic acid is largely similar to the glucose by structure, some of glucose may be extracted in the acetic acid during the extraction of ascorbic acid from sample, because of their structural similarity, glucose may also form the colored complex with DNPH as ascorbic acid. But actually no such interference is occurred which is evident from the following spectrum given in Fig. 2. From spectrum it is evident that there is no absorption peak around the interested peak at $280 \mathrm{~nm}$. Vitamin C is important to human health, and many species need a dietary source to stay healthy. The locally available citrus fruits such Orange, Tangerine, Sour Orange and Lemon are the excellent sources of vitamin C. The locally available vegetables which were analyzed contain relatively good amount of vitamin $\mathrm{C}$ and a good source of vitamin $\mathrm{C}$. The method is simple and offers an excellent method for the determination of total vitamin $\mathrm{C}$ in fruits and vegetables.

\section{Conclusion}

The locally available some fruit juices are natural sources of vitamin C under the study are generally agree with international samples. Indicated that the juice samples were of good quality and had acceptable value comparatively with amount labeled as in case Rayhan. The great amount of vitamin C recorded in case Mixed Fruit juice (Don Simon) was $40.82 \pm 0.63$ and $47.12 \pm 0.42$ for Peach Alain.

\section{Acknowledgements}

We are grateful to the Department of chemistry, Benghazi University for giving necessary facilities.

\section{References}

[1]. Bendich A.,(1997):Vitamin C health and disease.New York,pp.367-379.

[2]. Block G.,(1991): Epidemiologic evidence regarding vitamin C and cancer. Am. J.Clin. Nut. 54:1310S - 1314S

[3]. Block G.,(1992): The data support a role for antioxidants in reducing cancer risk. Nut. Rev., pp. $207-213$.

[4]. Feri B.,(1994): Reactive oxygen species and antioxidant vitamins: mechanisms of action. Am. J. Med., 97:Suppl. 3A, 5S - 13S

[5]. Geigertj J., D.S. Hirano and S.L. Neidleman,(1981): High Performance liquid Chromatographic method for the determination of Lascorbic acid and D - isoacetic acid. J. Chromatograph.,Vol. 206,pp. 396 - 399.

[6]. Groof J.L., S.S. Gropper and S.M. Hunt,(1995): The water soluble vitamins. In: advanced nutrition and human mechanisms. West publishing company, pp.222 - 237. Indian Pharmacopoeia,(1985): Photolithio Press, Faridabad, 49P

[7]. Jacobs M.M.,(1993): Diet, nutrition and cancer research: An overview, Nutrition Today, pp. $19-23$

[8]. Jaffe G.M.,(1984): Vitamin C, In: Machalinal ed. Handbook of vitamins. New York: Mercell Dekker Inc., pp.199 - 244

[9]. Lehinger Albert L. Principles of Biochemistry, CBS publishers and distribution Pvt. Ltd.

[10]. Levine M.,(1986): New concepts in the biology and biochemistry of ascorbic acid. New England. J. Med., Vol. $314, p p .892$ - 902.

[11]. Levine M.,Dhariwal KR,Wang Y and Park JB,(1995): Determination of optimal vitamin C requirements in humans. Am.J. Clin. Nut., Vol.62, pp.1347S-1356S

[12]. Levine M.,Conry-Cantilena C,Wang Y, Welch R W,Washko P W, Dhariwal KR, Park JB,Lazarev A,King J and Cantilena LR, (1996): Vitamin C Pharmacokinetics in healthy volunteers, Evidence for a recommended dietary allowance. Proceedings of the National Academy of Sciences USA,Vol. 93,pp. 3704 - 3709.

[13]. Rahman M.M., Khan M.M., Murad A.T.M. and S.A. Begum, (2005): Determination of vitamin C content in various fruits and vegetables by UV-spectrophotometric method at Sylhet area, Bangaladish. J.Environ. Sci., Vol. 11, pp.190 - 193

[14]. Rath M.,(1993): Eradicating Heart Disease. Gealth Now, San Francisco, C.A.

[15]. Riemschneider R., M.Z. Abedin and R.P. Mocellin, (1976): Qualitats and stabilisierungprufung hitzekonservierter Nahrungsmittel unter verwendung von Vit. C als kriterium - Mitt I. Alimenta, Vol. 15,171p.

[16]. Sies H. and S. Wilhelm, (1995): Vitamins E, C, Beta - Carotene and other carotenoides as antioxidants. Am.J.Clin.Nut., 62:315S$321 \mathrm{~S}$.

[17]. Shafqat ullah, Arshad Hussain, Javid Ali, Khaliqurrehman and Asad ullah, (2012): A Simple and Rapid HPLC Method for Analysis of Vitamin-C in Local Packed Juices of Pakistan. Middle-East Journal of Scientific Research., Vol. 12, 8: pp1085-1091.

[18]. Veasey R.L. and T.A. Nieman, (1980): Chromatographic detector applied to ascorbic acid determinations. J.Chromatogr., Vol.200, pp. $153-162$.

[19]. Weber P., A. Bendich and W.Schalch,(1996): Vitamin C and human health - a review of recent data relevant to human requirements. Intl.J.Vitam. Nutr. Res., Vol. 66, pp.19-30.

[20]. Woodall A.A. and B.N. Ames,(1997): Diet and oxidative damage to DNA. The importance of ascorbate as an antioxidant. In: Packer L. and J.Fuchs, Eds. Vitamin C in health and disease. New York: Marcel Dekker INC, pp. 193 - 203. 